\title{
Utilizing ERT and GPR to Distinguish Structures Maleficence the Constructions in the New Administrative Capital, Egypt
}

\author{
Adel Kotb ${ }^{1, ~ *, ~ A l h u s s e i n ~ A d h a m ~ B a s h e e r ~}{ }^{1}$, Ahmed Nasser ${ }^{2}$, Mohamed Ramah ${ }^{3}$ \\ ${ }^{1}$ Geology Department, Faculty of Science, Helwan University, Ain Helwan, Cairo, Egypt \\ ${ }^{2}$ Geophysical Exploration Department, Desert Research Center, Cairo, Egypt \\ ${ }^{3}$ Geophysical Sciences Department, National Research Centre, Cairo, Egypt
}

Email address:

Adelkotb@science.helwan.edu.eg (A. Kotb), alhussein.adham@science.helwan.edu.eg (A. A. Basheer),

dr.nasr_dre@yahoo.com (A. Nasser),m.ramah94@gmail.com (M. Ramah)

${ }^{*}$ Corresponding author

\section{To cite this article:}

Adel Kotb, Alhussein Adham Basheer, Ahmed Nasser, Mohamed Ramah. Utilizing ERT and GPR to Distinguish Structures Maleficence the Constructions in the New Administrative Capital, Egypt. Earth Sciences. Vol. 10, No. 5, 2021, pp. 234-243.

doi: $10.11648 /$ j.earth.20211005.15

Received: September 15, 2021; Accepted: October 11, 2021; Published: October 29, 2021

\begin{abstract}
The new administrative capital (NAC), as decided by the Egyptian government's proposed planning, is placed 45 kilometers east of Cairo. According to Egyptian government strategies, this city will be the country's future governmental and economic hub. Ministries, crucial government agencies, and sectors are all expected to be represented on the site. The future capital's total land area is around 700 square kilometers. It is projected that there are five million people living there, this population could rise to seven million people. The skyscrapers sector in the New Administrative Capital is the subject of the research. To detect near-surface structures at the chosen building site, nine Electrical Resistivity Tomography (ERT) profiles and twenty-four Ground Penetrating Radar (GPR) profiles were used in this study. After the necessary and appropriate processing, the results that extrapolated from all measured profiles of both tools, demonstrated that the research region can be separated into two different shallow layers. The (Higher Miocene) sandy limestone rock makes up the main first surface layer with thickness about 4 meters. The second layer consists of silty shale rock with thickness about 12 meters in some places. This The most obvious features that had an impact on building were normal faults in the WNW and ENE directions, with minor fractures between them, as well as a few shale lenses can reach diameters of 3 to 4 meters. Additionally, the retrieved findings from the two geophysical tools demonstrate that the shape and thickness of the inferred layers are in satisfactory correlation.
\end{abstract}

Keywords: ERT, GPR, Shallow Subsurface Structures, The New Administrative Capital City, Egypt

\section{Introduction}

The New Administrative Capital is a government proposal that was crystallized to reduce the overcrowding in Cairo, which is the ancient capital of Egypt. The transfer of government headquarters and ministries with all their employees will allow change the idea of centralization in ending government procedures within the old capital (Figure 1).

This will allow people to change their traditional ideas of seeking housing next to government agencies to end their daily procedures. This step will be the first stage to create a new urban community characterized by the presence of all services near it. Since the most important steps involved in establishing new cities are concrete buildings and basic infrastructure supplies, the most important thing that should be studied is the nature of the soil. The study area was chosen to apply a geophysical measurement to find out the most important rock structures that may affect the nature of the soil. The electrical resistivity tomography method and the ground penetrating radar have the advantage of easily 
determining the susceptibility of the surface soil to the structures affecting it [1-4]. The ERT method can be applied to several uses such as mapping geological changes, including the diversity and distribution of soil rocks (for example, clay versus gravel), the presence and irradiation of surface groundwater, fracture areas, locations of soil saturation change, areas of increased salinity and their overlap by fresh groundwater and studying some cases of groundwater pollution. ERT can be used for mapping fundamental rock depths, mapping top-of-bedrock and geometries [5-7]. Preferably, ERT is used for mapping cavities such as caves, karstic sewers, and decaying sewers. There are many factors that are affected greatly by electrical methods such as subsurface geochemistry, particle distribution, groundwater chemistry and the presence of pollution elements $[8,9]$. Common uses of GPR systems are in mapping the distribution of basic underground facilities, determining the thickness of soil or rock layer, impacting fractures in rocks, designating karst characteristics such as cavities and voids, underground storage tanks (UST), lava tubes, discovering ancient foundations, archaeological detection, mapping debris and identifying other obstacles to construction $[10,11]$. Despite the many successful applications of the GPR method, there are many obstacles and factors that limit and diminish its results, such as clay soil, saturated soil, saline groundwater, and lack of penetration outside or through metal objects, the effect of alkalis on the surface of the earth $[12,13]$. Therefore, an understanding of the proposed site for application to it, the sedimentary environment and the geological conditions is essential and extremely important in determining the likelihood that the GPR method will be able to meet the project objectives when applied in a specific manner. There are several reasons for choosing the location of the study, which is that there was a proposal to construct two buildings (No. 5 and 6) on a somewhat heterogeneous rocky layer in the New Egyptian Administrative Capital, after the completion of the construction of the concrete foundations, several cracks appeared after a period of hardening and drought. Because of the previously known information about the study area, which is that the sedimentary record of the area is represented by the Oligocene and Miocene rocks, and the cornerstone of the new administrative capital was cut by many faults in the northwest, northwest and ENE, but most of them are geologically old and do not pose a seismic threat. Few of these bugs have seen activity in the past 100 years. Therefore, analysis of topography, geological structures, and surface geological processes is essential in land management perspectives, especially in such dynamic and complex geological areas.

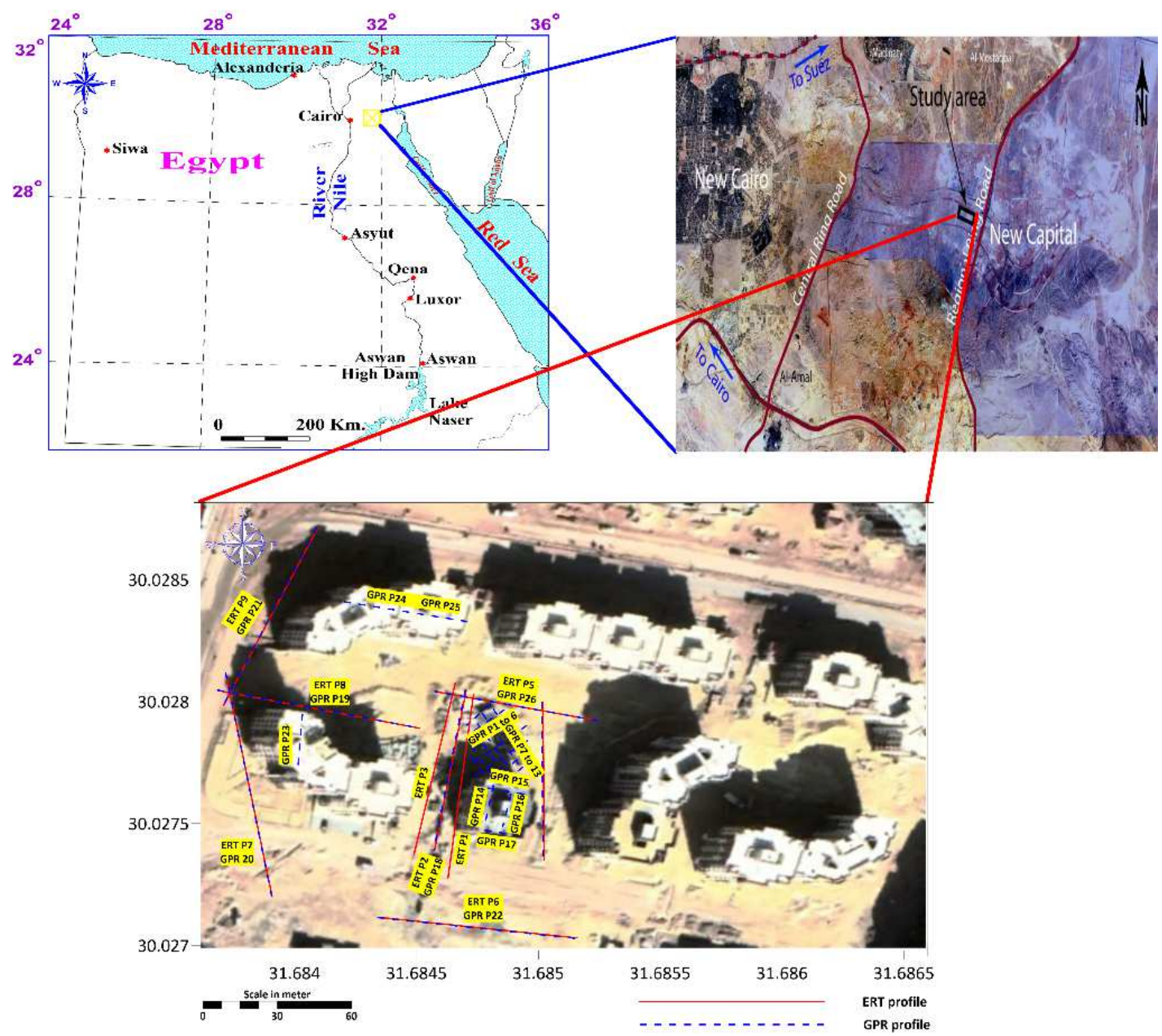

Figure 1. Spatial Location of the area under study with field work distributions. 


\section{Geological Setting and Stratigraphy}

The stratigraphic succession for the most part in the study area ranges, in geological age, between the late-Early Eocene and the Oligocene. The Neogene sediments are exposed outer in the study area at Wadi Ghoweiba, Wadi Hagul, and to the north at Gebel Gharra, Gebel Iweibed, and Gebel Homeiyra. Quaternary sediments compose of alluvial terraces and cover the floors of wadis. The middle part of the Cairo-Suez district composes of a nearly parallel, high mountain edges trending in an E-Wand NW-SE directions with low-lands in the middle. The Middle Eocene rocks mostly assemble the mountains and high scarps disregarding both sides of the Qattamiya-Ain Sukhna road, whereas both the Upper Eocene and Oligocene sediments cap the low topographic areas as grabens. A simplified geological map of the study area is drawn in figure 2 .

Beside the sedimentary rocks, some volcanic sheets are mostly basalts, it evidenced from numerous places along Cairo-Suez district $[14,15,16]$. They were observed at Gebel Abu Treifiya, surrounding it from all sides excluding the northern face and also noted to the south of Gebel Umm Reheiat along the Qattamiya-Ain Sukhna road, comprises well-known hillocks $[17,18]$. Basalt extrusion was the result of rejuvenation of the normal faults in E-Wand NW-SE direction for the period of late Oligocene and Early Miocene [19]. These basalts were given out by [20] using K/Ar method, to the late Oligocene - early Miocene (Aquitanian; $22 \pm 2$ Ma.).
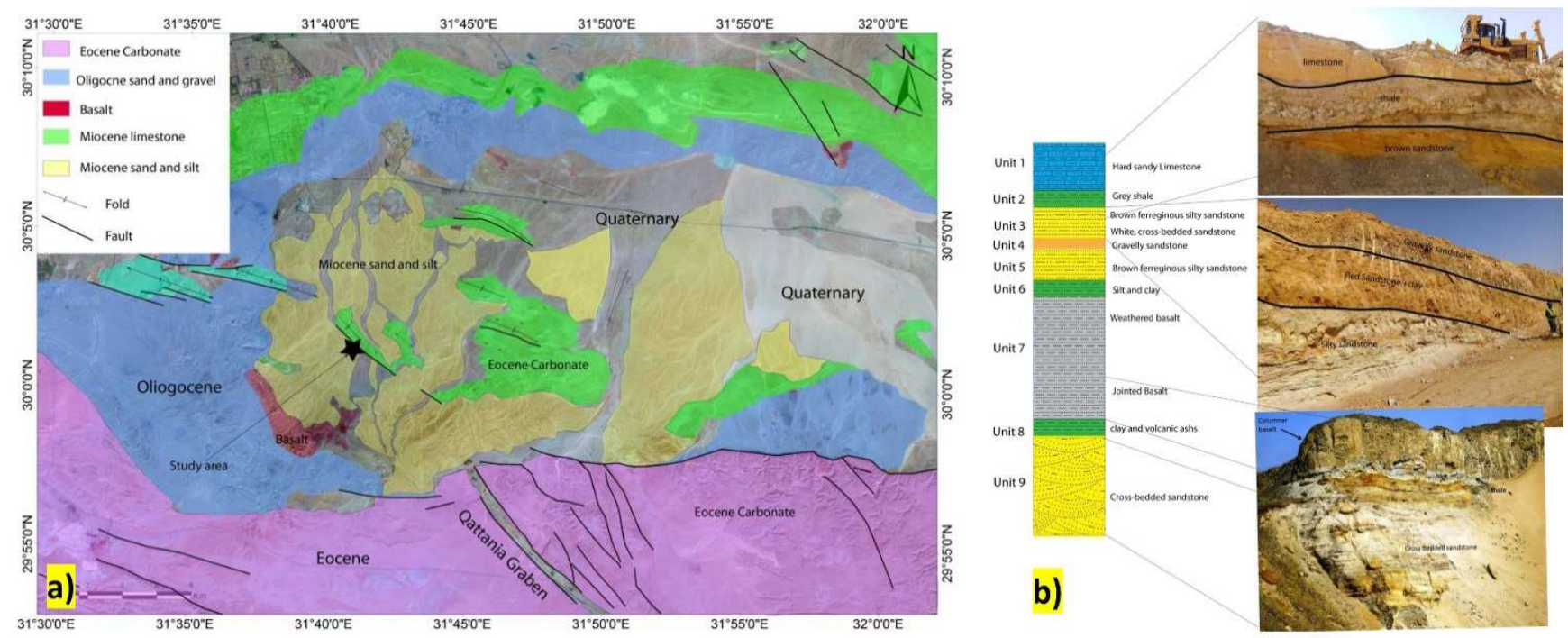

Figure 2. The General geological setting a), the stratigraphical setting of the study area, b) after [19].
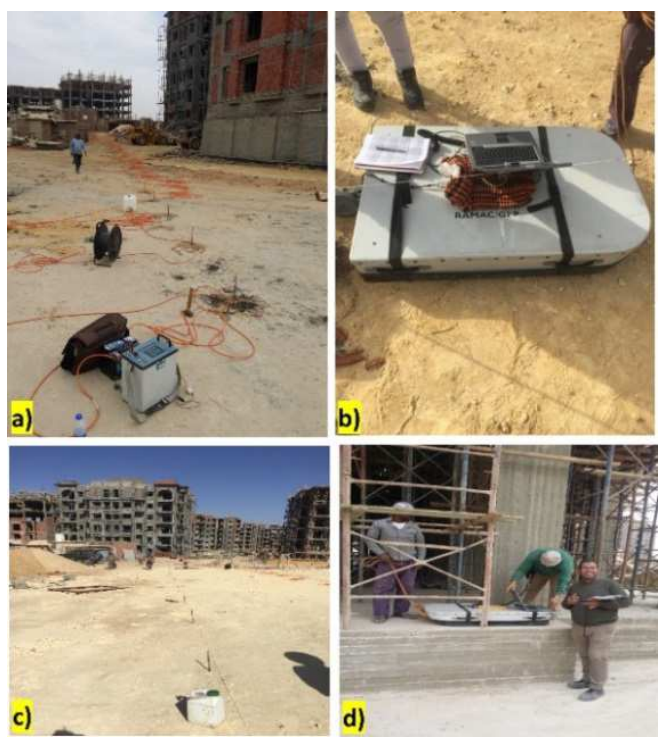

Figure 3. Documenting the field measurements and Devices a) [23] instrument and its accessories, b) [24] GPR and its accessories, c) the distribution of electrodes array in survey of ERT profile no. 7, d) survey of GPR profile 14

\section{Methodology}

\subsection{Electrical Resistivity Tomography [ERT]}

ERT is an electrical test method based on the electric current induction of layers of earth using two electrodes. The voltage drop is then measured and recorded using two other electrodes [4]. Many different electrode array configurations have been designed to reach a measurement of specific depth points in the soil. All array configurations have a uniform target, which is the collection of data whose results can be applied in estimating the different changes in the ground resistance values in the lateral and vertical dimensions.

ERT in 2D imaging survey can overcome resistance changes in both the horizontal and vertical dimensions along 9 scan lines. For this reason, the two-dimensional geoelectric imaging technique was chosen for application in the study area. Wenner's method of distributing electrodes yields an array with the fewest possible data compared to other common arrays [21, 6, 22]. This distribution has the ability to measure in noisy areas which 
necessitate that accurate vertical accuracy be important and necessary, and therefore it was used in the present study. The scanning of nine lines (Figure 4) have been used a multi-electrode system which is linked to the [23] ammeter through a multi-core cable (Figures 3 a \& c). There was a small computer integrated with an electronic switching unit to automatically identify the four related electrodes for each measurement used.

\subsection{Ground Penetrating Radar [GPR]}

The technique of GPR method is based on a physical principle of propagating waves that send and receive electromagnetic waves (EM or radio waves). The common form of using the GPR method is the zero-reflection scan mode, in which the EM signal is almost as a vertical travel path, but it can be measured by configuring the EM signal in the offset reflection mode as well $[10,11]$. There are a lot of GPR systems and antennas that were introduced by commercial companies. The range of the paired terrestrial antennas used in imaging the Earth ranges from a center frequency of 25 to $1500 \mathrm{MHz}$. Air-coupled antennas, which are used in paving and concrete imaging, can have a frequency of up to $2.2 \mathrm{GHz}$. The user can increase the low frequency range with more depth investigation, but this increase is unfortunately at the cost of target accuracy; On the other hand, higher frequencies have tremendous accuracy, but they have limitations in the depth of investigation [24] (Figures 3 b \& d).

A Mala-Radar system was used with a $200 \mathrm{MHz}$ antenna and a scanning wheel, manufactured by Malaya. The $200 \mathrm{MHz}$ antenna was selected for the purpose of obtaining maximum detail and highest resolution at the top 3-10 meters (Figure 5). Several sectors were surveyed in the same places of electrical imaging and some places over the concrete blocks in the study area, so that the anomalous feature resulting from the impedance imaging method is discovered. In each sector, the scanning was done by a method of rotation and a reversal in the direction of the scan (back and forth) so that the scanning lines were spaced every $5 \mathrm{~cm}$ and a length 130 meters. The data set for the study area was completed with 26 a GPR scan lines and the time windows were $120 \mathrm{~ns}$, with 20 scans per meter, and 512 samples per scan (Figures 3 b \& d).

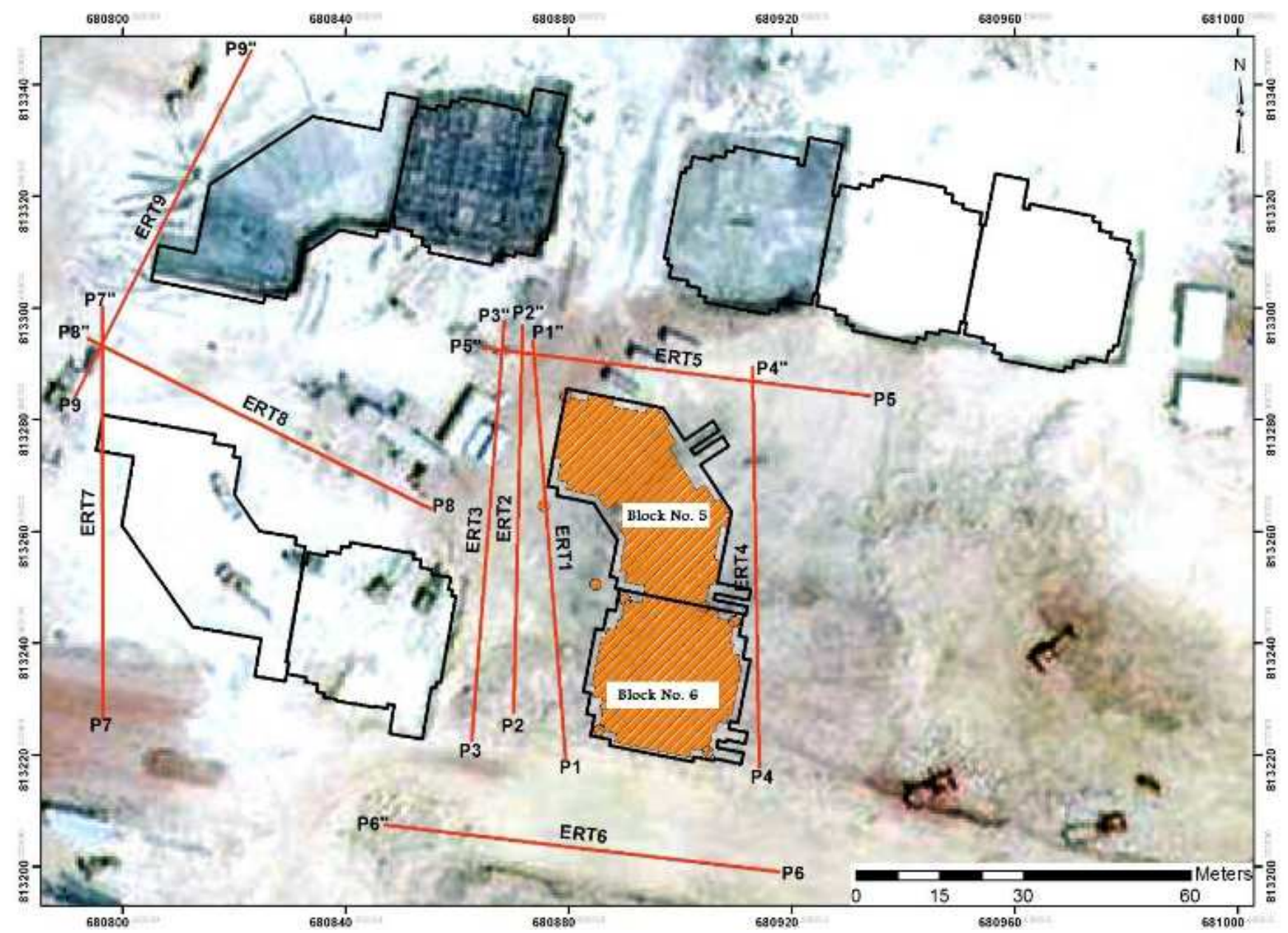

Figure 4. Spatial distribution of the measured ERT Profiles. 


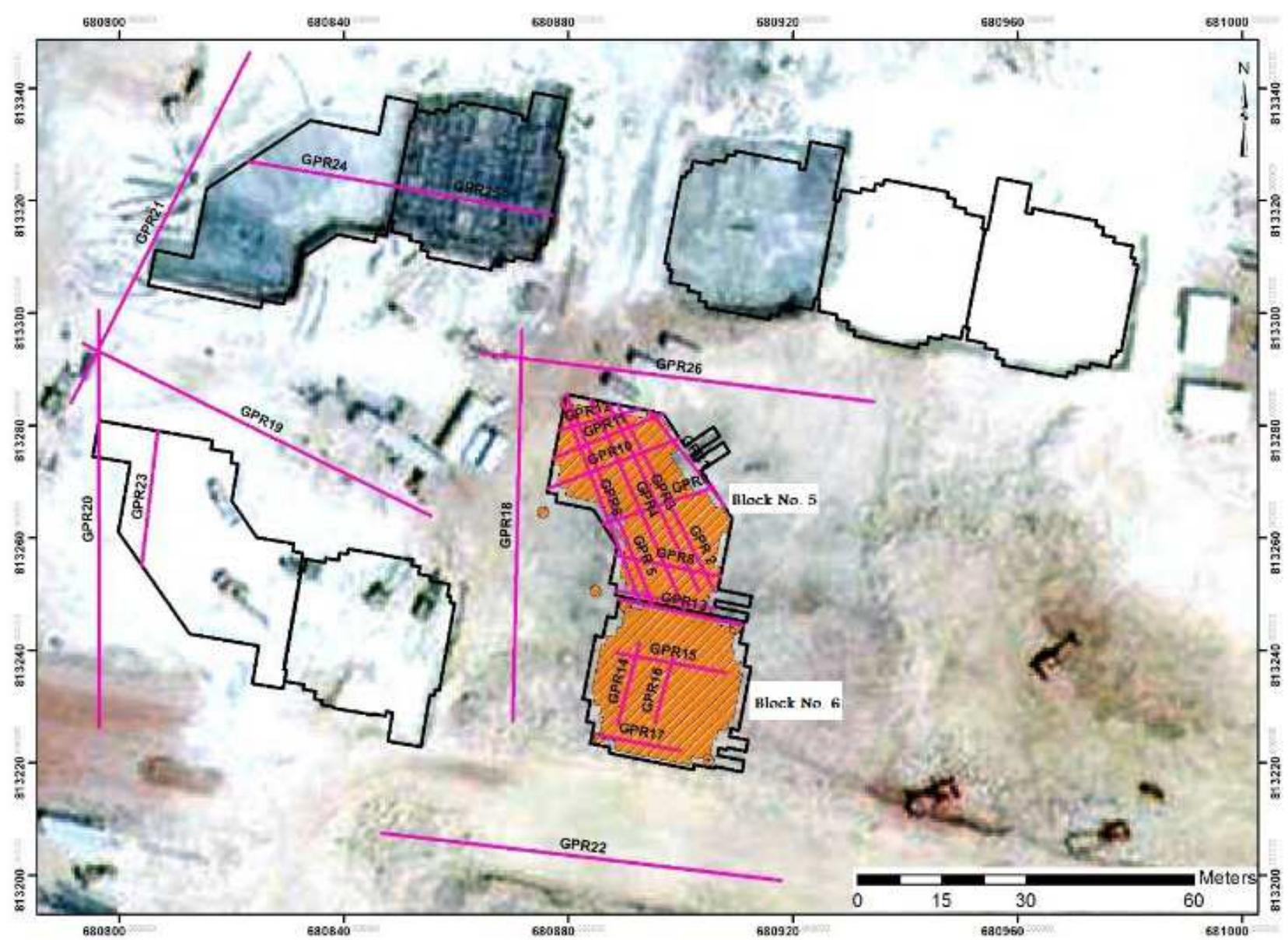

Figure 5. The places of GPR Profiles distribution in the study area.

\section{Data Interpretation and Discussion}

\subsection{ERT Data}

The ERT method is considered one of the most easy and applicable geophysical techniques, especially regarding clarifying temporal and spatial changes in the content of interfering water in the soil, describing soil slip problems, soil thickness changes, calculating the lateral extension, and measuring the variable depth of soil $[1,2,3,4,8]$. The computer software's [25], edited in 1998, ([26]; Loke, 2002) are used to interpret resistivity data, and these programs have the ability to both drawing the electric cross sections along each recorded profile in the study area and calculating the subsurface layers' parameters such as (depth, and resistivity under each electrode). Four layers can be defined in the study area according to the general view up of the constructed cross sections. The "first" surface upper layer consists of (Upper Miocene) sandy to Marly limestone rock. That layer is located above the second layer of silty shale rock. It is known that the two-dimensional sectors of the electrical measurements were carried out on non-built land, but around concreted buildings, and the results of the two-dimensional geo-electrical measurements in the study area were interpreted qualitatively and quantitatively and presented in the form of different crosssectional shapes in order to accurately clarify the subsurface conditions more accurately As follows:

1) The qualitative explanations of the results of the geoelectric resistivity measurements show both horizontal and vertical change in the values of electrical resistivity and the thickness of the layers. It is clear as shown by the geo-electrical cross-section from P1 to P4 (Figure 6).

2) It is evident that there is a noticeable horizontal change in some sectors with the values of geoelectric resistivity between 2 and 78 Ohm.m, whereas areas with values from 2 to $5 \mathrm{Ohm} . \mathrm{m}$ indicate the presence of layers of the shale or marl, although areas with values between 16 and $78 \mathrm{Ohm} . \mathrm{m}$ indicate the presence of Layers of limestone and Marly limestone.

3) The first layer, consisting of the shale and the marl, is detected in the form of lenses in cross-sections numbers $(1,2,3,4,5$ and 8$)$ below the base-foundation level as shown in the geo-electrical cross-section (Figure 6). This layer has not been monitored in cross-sections nos. 6, 7 and 9 (Figure 7).

4) The second layer, consisting of limestone and Marly limestone, appears in all cross-sections, they also show some subsurface geological structures represented by separators and crevices.

5) The effects of the cracks extended to the third layer. There is a shift in displacement that differ from profile 1 , 4 , and 9, the cracks outline at distances 14, 24 and 42. 


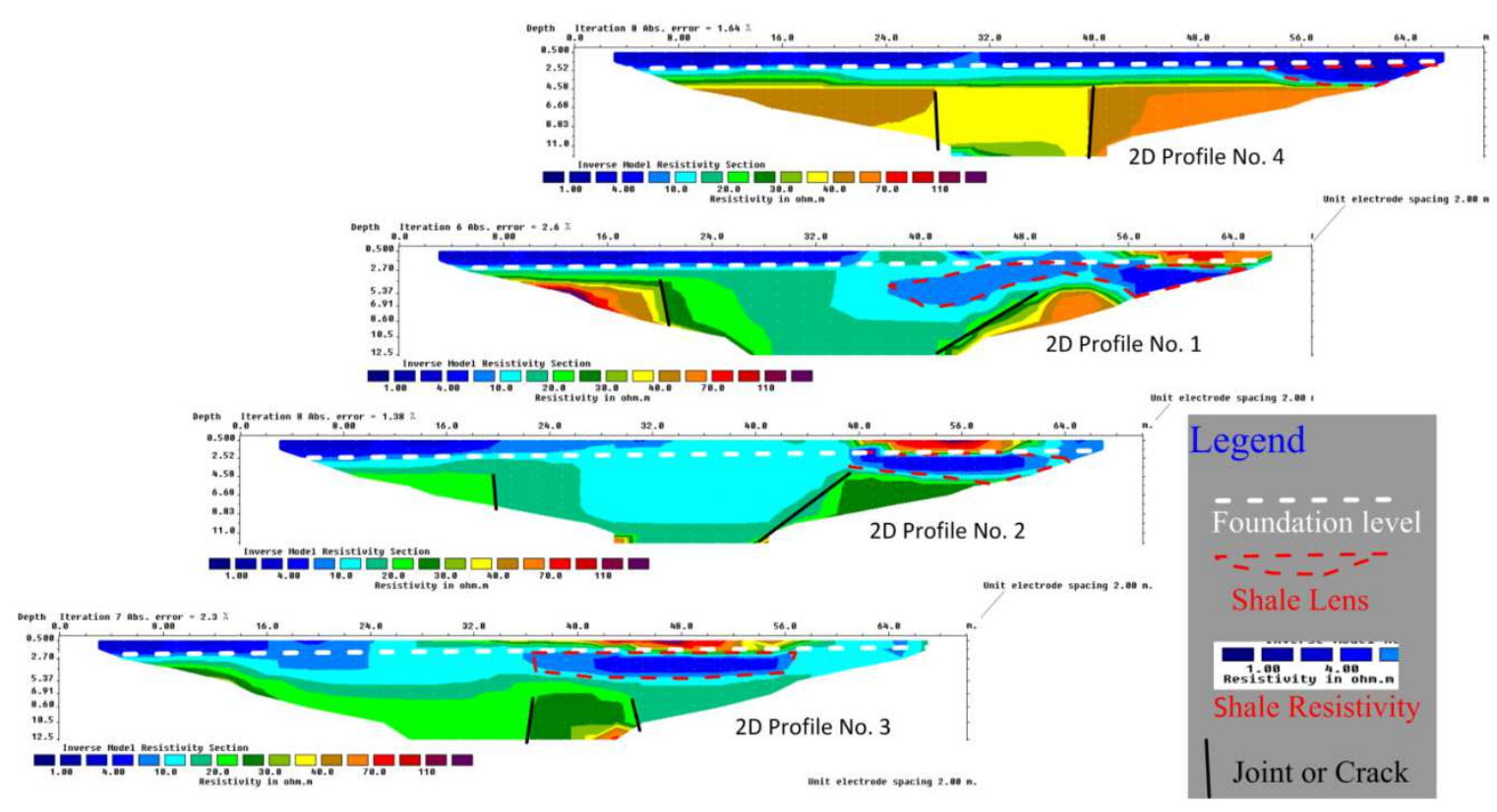

Figure 6. Interpreted ERT profiles No. 1, 2, 3, and 4.
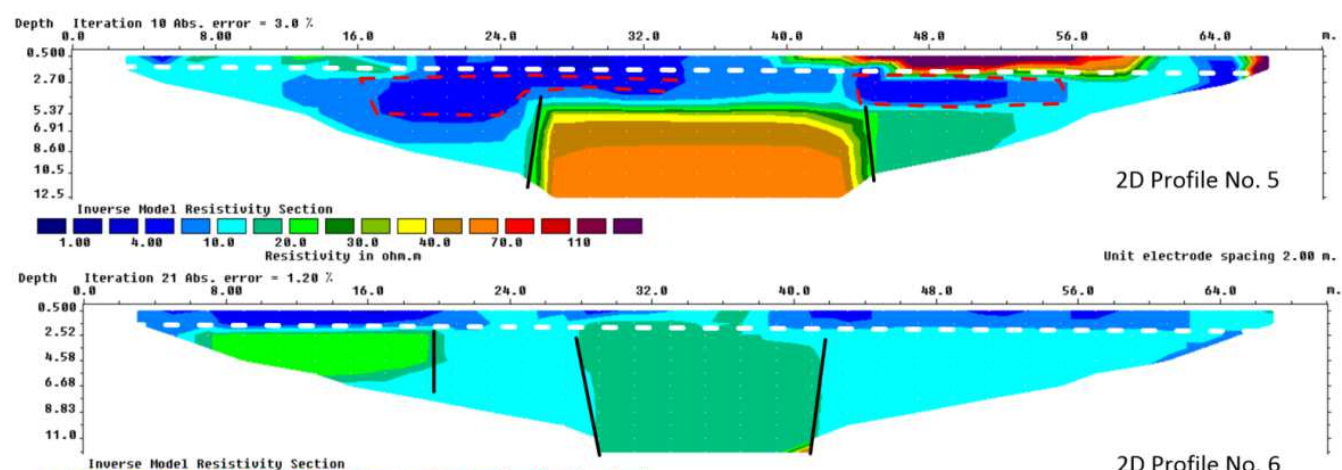

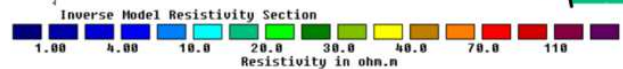

2D Profile No. 6

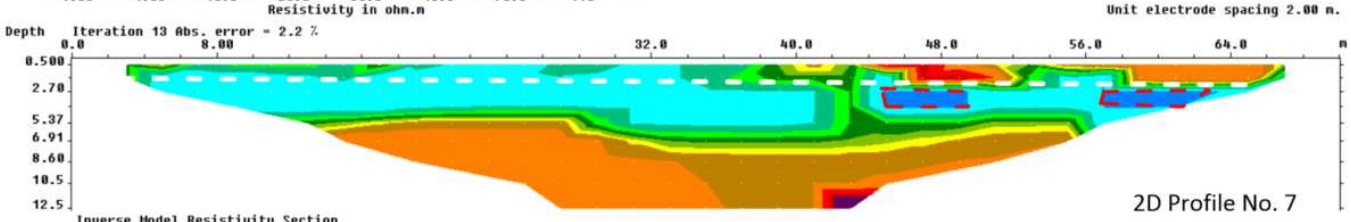

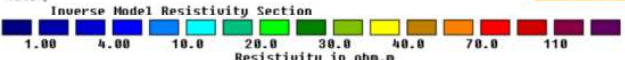

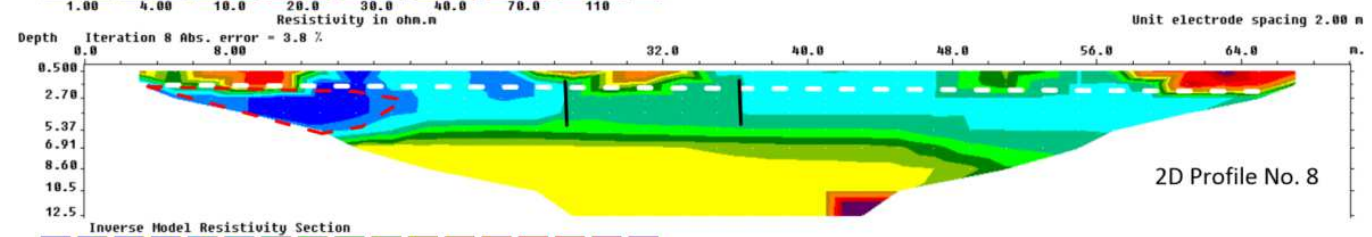

$\square_{1.00}^{\text {Inverse Hoder Resistivity Section }}$

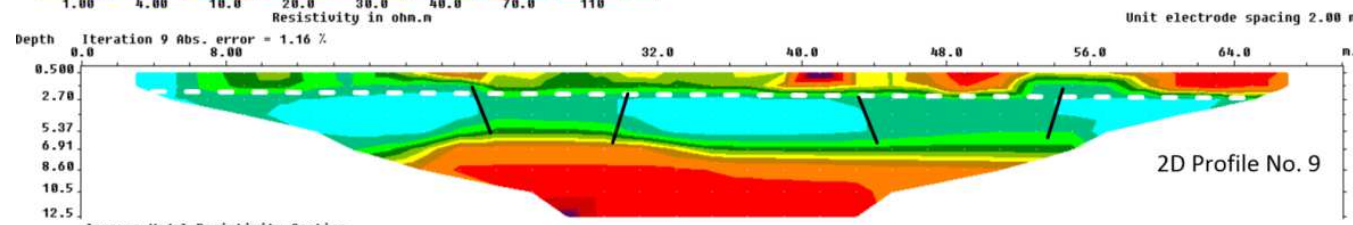

1..5 Inverse Mode1 Resistivity Section

Unit electrode spacing $2.00 \mathrm{n}$

Legend $\quad$ Shale Lens $\quad$ Shale Resistivity $\mid$ Joint or Crack

Figure 7. Interpreted ERT profiles from 5 to 9. 

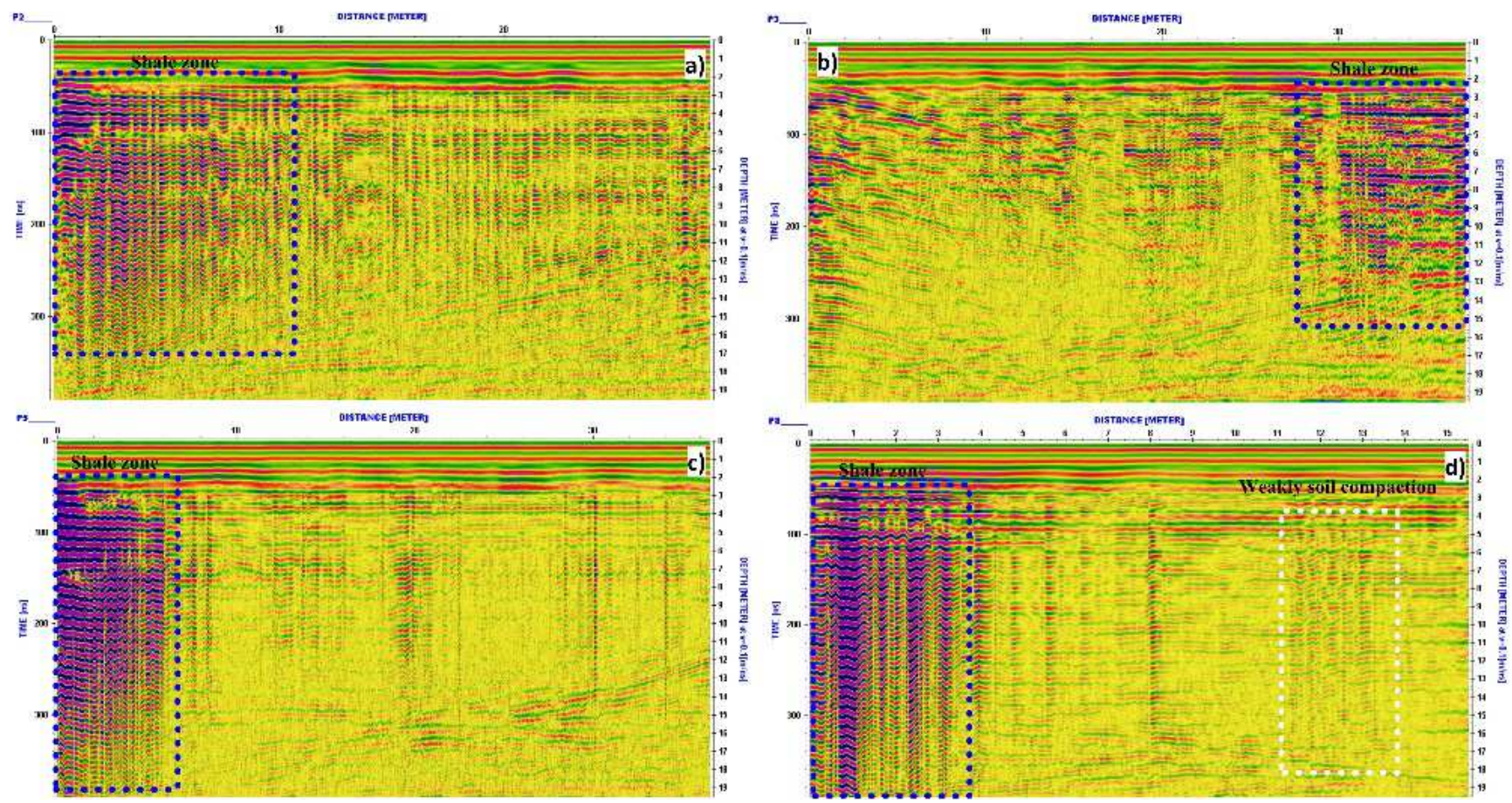

Figure 8. Examples of the interpreted GPR profiles 2, 3, 5, and 8 listed as a, b, c, and d respectively.
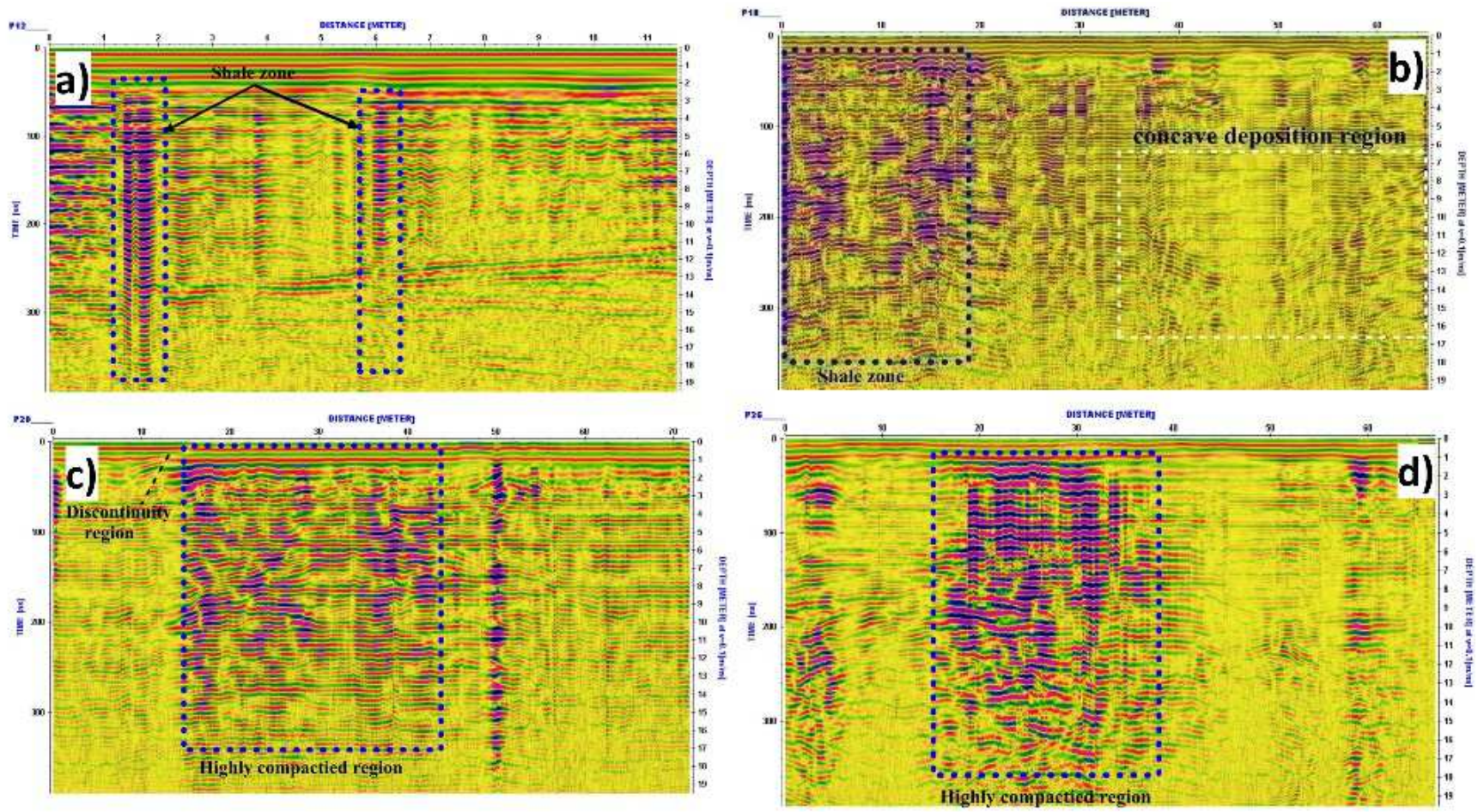

Figure 9. Examples of the interpreted GPR profiles 12, 18, 20, and 26 listed as $a, b, c$, and d respectively.

\section{2. (GPR) Data Interpretation and Discussion}

The values of the insulation measurements, using the pyrometer, are relatively consistent and have a relationship in line with the ability of the rock to retain some amount of moisture for making measurements in nature [28]. Unfortunately, the application of the pyrometer test in the field was limited due to the fact that this test requires manual measurement for each site where the measurement is performed with a device because data collection must be done manually in every location where measurements are taken with the radar device, which limits and hinders data collection. For this reason, the use of GPR is the most effective way to evaluate cracks and fractures in areas where construction has already taken place. A GPR [24] system with an antenna and a laptop connected to trolley handles was used to collect data on the study area. Using GPR, the 
extent of ground cracks spacing can be measured by comparing the amplitude of the reflected signal from the surface with the amplitude of the reflected signal from cohesive soil at the same measurement site. (as the reference) (DC values depend on the time taken to arrive, the amplitude of the current, and the pulses reflected from the reached surfaces, which are referred to as the radar wave. These waves display the amount of DC current and the thickness of the layers within the soil $[28,29]$. It is worth noting that the radar data cannot be used immediately for interpretation and exploration, because typical terrestrial radar measurements contain reflection features, noise, and chaotic reflections resulting from the antenna "resonance", differences in the power coupling to the ground, and multiple reflections that occur between the antenna and the Earth's surface, as well as 'Noise' in the background [30, 31, 32]. The final steps in data processing include converting the radar data into usable images. Often this requires a significant simplification of the complex block of GPR data $[12,13]$. The work areas were treated in two stages, the first stage was to confirm the anomalous features that could be found in the GPR field sections. The complete GPR dataset was analyzed using [33] software for post-processing operations (Figures 8 and 9). In the second stage, several processing steps were applied including background removal to remove horizontal lines caused by surface reflections, band-pass filter for highfrequency component removal, F-K filter and automatic gain control. The processed geo-radar data shows that cracks and joints are clearly visible. Some sectors show weaknesses in concrete, as in profiles numbers $(8,9$ and 12), and some profiles show no effect of cracks and joints (Figures 8 and 9).
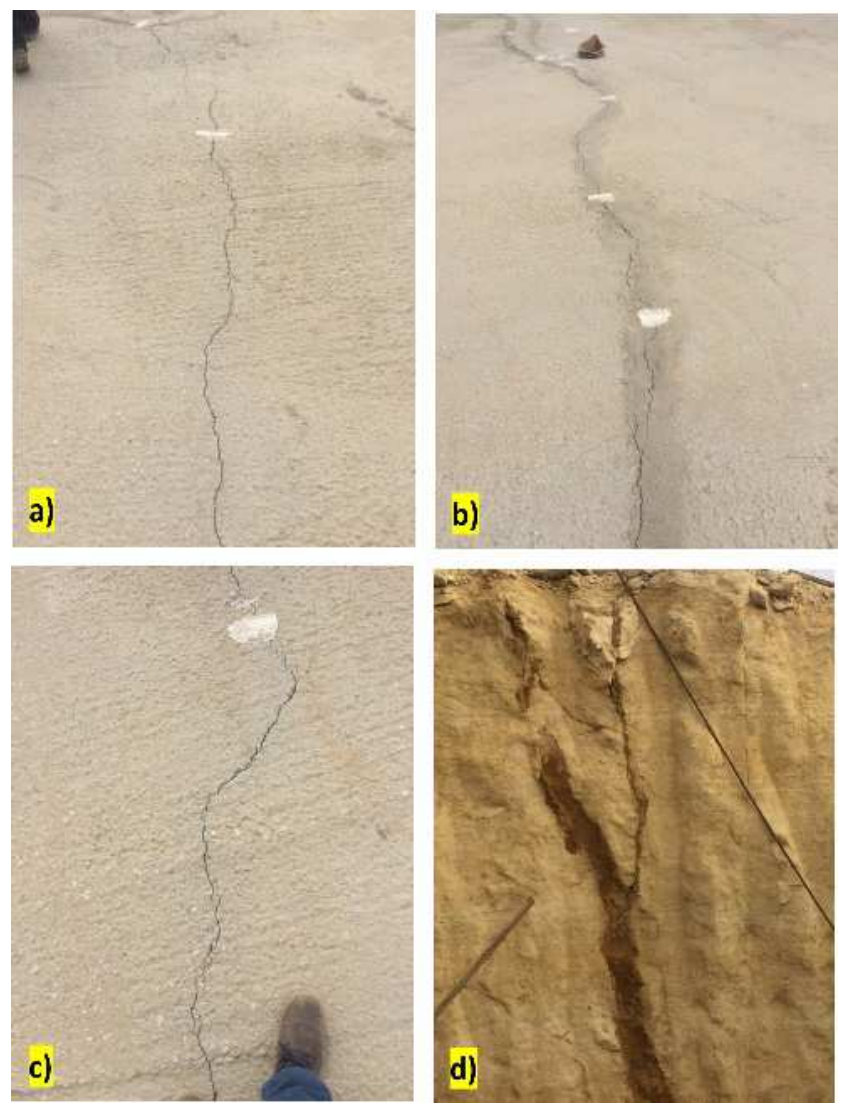

Figure 10. Realistic pictures from the study site showing the emergence of cracks in the concrete surfaces affected by the superficial structures.

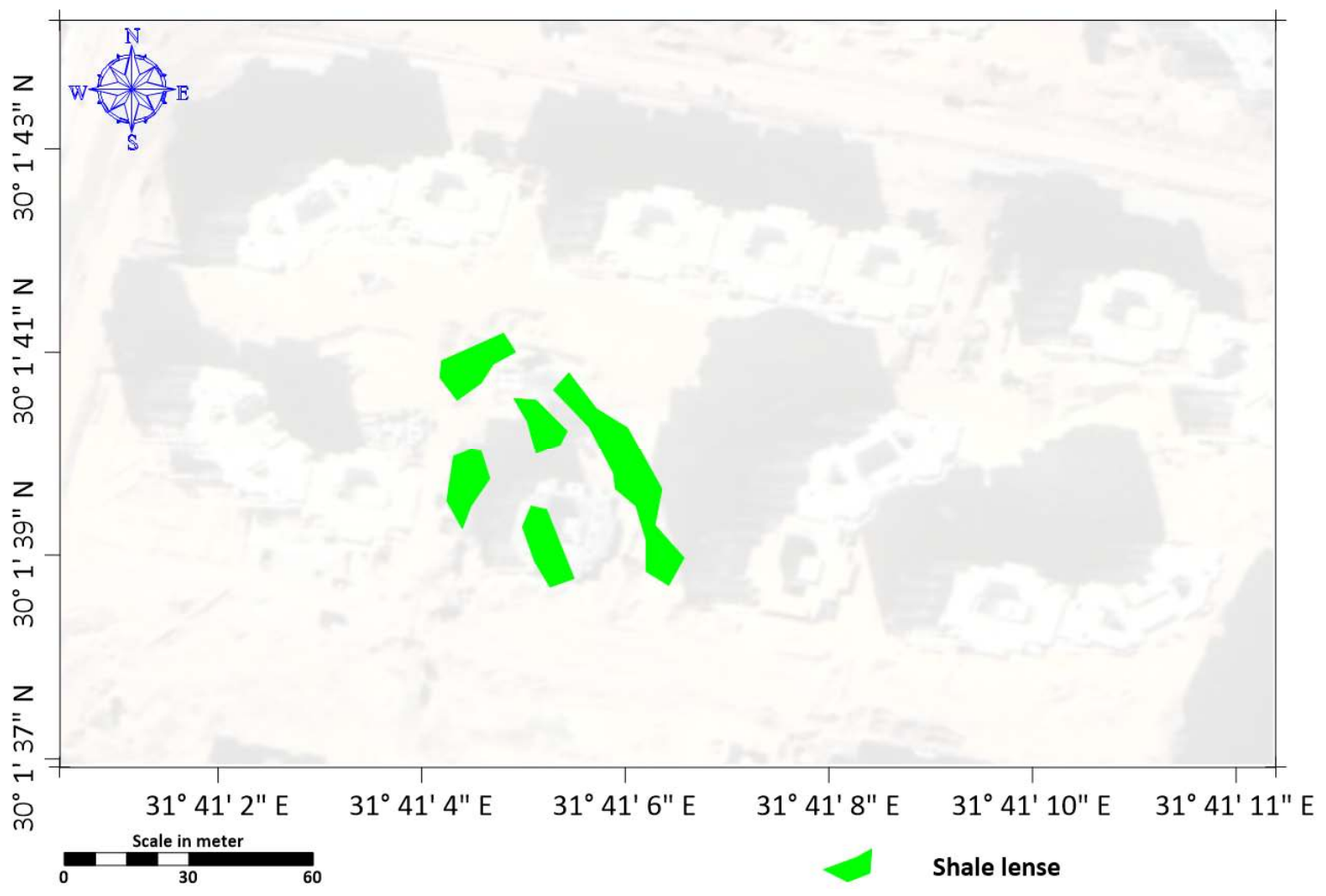

Figure 11. The distribution of shale lenses detected by geophysical survey in the study area. 


\section{Conclusion and Recommendation}

From all the above geophysical surveys of the area concerned with the study, the following results were obtained:

1) The Miocene rocks constitute the most prominent stratigraphic units in the study area.

2) The study area consists of limestone-to-Marly limestone with the intersection of shale.

3) ERT and GPR succeeded in providing detailed information about the upper (shallow) portion of the subsurface (approximately 8 to $20 \mathrm{~m}$ thick).

4) It can distinguish local rock heterogeneity and the cause of cracks appearing in concrete foundations.

5) Shale appears in the study area as a lens.

6) The limestone to Marley limestone layer is affected by many joints, fissures, and concave sedimentation areas (Figure 10).

7) These sub-surface structures are located below the foundation depth of Building No. 5 and 6 (in the study area).

8) These many joints, fissures, and concave cause cracks in concrete in buildings.

9) It was recommended to exclude building sites and to change sites after concrete structures, or take all engineering precautions according to the above data (Figure 11).

\section{References}

[1] Gance, J., Malet, J. P., Dewez, T., \& Travelletti, J. (2014). Target Detection and Tracking of moving objects for characterizing landslide displacements from time-lapse terrestrial optical images. Engineering geology, 172, 26-40.

[2] Uhlemann, T. H. J., Lehmann, C., \& Steinhilper, R. (2017). The digital twin: Realizing the cyber-physical production system for industry 4.0. Procedia Cirp, 61, 335-340.

[3] Crawford, M. M., \& Bryson, L. S. (2018). Assessment of active landslides using field electrical measurements. Engineering Geology, 233, 146-159.

[4] Crawford, M. M., Bryson, L. S., Woolery, E. W., \& Wang, Z. (2018). Using 2-D electrical resistivity imaging for joint geophysical and geotechnical characterization of shallow landslides. Journal of Applied Geophysics, 157, 37-46.

[5] Loke, M. H., \& Barker, R. D. (1996). Rapid least-squares inversion of apparent resistivity pseudosections by a quasiNewton method 1. Geophysical prospecting, 44 (1), 131-152.

[6] Loke, S. (2006). Context-aware pervasive systems: architectures for a new breed of applications. CRC Press.

[7] Perrone, D., \& Favaro, P. (2014). Total variation blind deconvolution: The devil is in the details. In Proceedings of the IEEE Conference on Computer Vision and Pattern Recognition (pp. 2909-2916).

[8] Yilmaz, F., Özdemir, N., Demirak, A., \& Tuna, A. L. (2007). Heavy metal levels in two fish species Leuciscus cephalus and Lepomis gibbosus. Food Chemistry, 100 (2), 830-835.
[9] Akpan, S. B., \& Patrick, I. V. (2015). Does Annual Output of Palm oil, Palm Kernel and Rubber correlate with some Macroeconomic Policy variables in Nigeria. Nigerian Journal of Agriculture, Food and Environment, 11 (1), 66-72.

[10] Evans, C. D., Freeman, C., Cork, L. G., Thomas, D. N., Reynolds, B., Billett, M. F.,... \& Norris, D. (2007). Evidence against recent climate-induced destabilisation of soil carbon from 14C analysis of riverine dissolved organic matter. Geophysical Research Letters, 34 (7).

[11] Transportation Engineering, Part B, (2020): Pavements, Vol. 146, No. 3, 2020, p. 04020054.

[12] Young, R. A., \& Sun, J. (1999). Revealing stratigraphy in ground-penetrating radar data using domain filtering. Geophysics, 64 (2), 435-442.

[13] Annan, A. P. (2005). Ground-penetrating radar. In Nearsurface geophysics (pp. 357-438). Society of Exploration Geophysicists.

[14] Bishay, A. M. (1961). Gamma-Ray Induced Coloring of Some Phosphate Glasses. Journal of the American Ceramic Society, 44 (11), 545-552.

[15] Al-Ahwani, M. M. (1982). Geological and sedimentological studies of Gebel Shabrawet area, Suez Canal district, Egypt.

[16] Al Anazi, A., \& Al Issawi, W. (2009). Extra-axial primary intracranial cerebral lymphoma mimicking meningioma. Neurosurgery Quarterly, 19 (3), 214-216.

[17] El Safori, Y. A., Zalat, A. A., Eweda, S. A., \& Maih, A. M. (1997). Eocene facies and bryozoans of the Qattamia area, Egypt. J Geol Egypt, 41 (2A), 365-425.

[18] Patton, M. Q. (1994). Developmental evaluation. Evaluation practice, 15 (3), 311-319.

[19] Said, R. (Ed.). (2017). The geology of Egypt. Routledge.

[20] Meneisy. (1986). Mesozoic igneous activity in Egypt.

[21] Griffiths, D. H., \& Barker, R. D. (1993). Two-dimensional resistivity imaging and modelling in areas of complex geology. Journal of applied Geophysics, 29 (3-4), 211-226.

[22] Akpan, E. A., \& Moffat, I. U. (2017). Detection and modeling of asymmetric GARCH effects in a discrete-time series. International Journal of Statistics and Probability, 6 (6), 111119.

[23] SYSCAL Pro. http://www.iris-instruments.com/syscalpro.html

[24] RAMAC System, Mala Instruments. https://www.malagpr.com.au/x3m-system.html

[25] Loke, M. H. (1998). Res2dInv. Rapid 2D resistivity and IP inversion using the least-squares method, User Manual, Austin Tex, Advanced Geoscience Inc.

[26] Loke M. H. (2000). Electrical imaging surveys for environmental and engineering studies: a practical guide to 2D\&3D surveys, 61 .

[27] Loke, M. H., \& Dahlin, T. (2002). A comparison of the GaussNewton and Quasi-Newton methods in resistivity imaging inversion. Journal of Applied Gophysics, 49 (3), 149-162. 
[28] Lahouar, S. (2003). Development of data analysis algorithms for interpretation of ground penetrating radar data (Doctoral dissertation, Virginia Tech).

[29] Atlas, D. (Ed.). (2015). Radar in Meteorology: Battan Memorial and 40th Anniversary Radar Meteorology Conference. Springer.

[30] Conyers, A. J. (1997). The Church as Polis: From Political Theology to Theological Politics as Exemplified by Jurgen Moltmann and Stanley Hauerwas. Journal of Church and State, 39 (3), 584-585.
[31] Conyers, C., Doole, A., Vause, T., Harapiak, S., Yu, D. C., \& Martin, G. L. (2002). Predicting the relative efficacy of three presentation methods for assessing preferences of persons with developmental disabilities. Journal of Applied Behavior Analysis, 35 (1), 49-58.

[32] Goodman, D., Piro, S., Nishimura, Y., Schneider, K., Hongo, H., Higashi, N., \& Damiata, B. (2009). GPR archaeometry. Ground penetrating radar: Theory and applications, 479-506.

[33] REFLEXW version 9 software. https://www.sandmeiergeo.de/reflexw.html 